\title{
Water extract of Hedyotis Diffusa Willd suppresses proliferation of human HepG2 cells and potentiates the anticancer efficacy of low-dose 5-fluorouracil by inhibiting the CDK2-E2F1 pathway
}

\author{
XU-ZHENG CHEN ${ }^{1}$, ZHI-YUN CAO ${ }^{1}$, TUAN-SHENG CHEN ${ }^{2,3}$, YOU-QUAN ZHANG ${ }^{4}$, \\ ZHI-ZHEN LIU ${ }^{1}$, YIN-TAO SU ${ }^{5}$, LIAN-MING LIAO ${ }^{1}$ and JIAN DU ${ }^{1}$ \\ ${ }^{1}$ Academy of Integrative Medicine, Fujian University of Traditional Chinese Medicine, Fuzhou 350108; \\ ${ }^{2}$ Agricultural Product Quality Institute, Fujian Agriculture and Forestry University, Fuzhou 350002; \\ ${ }^{3}$ Hospital of Fujian Agriculture and Forestry University, Fuzhou 350002; ${ }^{4}$ The Second Affiliated Hospital, \\ Fujian University of Traditional Chinese Medicine, Fuzhou 350003; ${ }^{5}$ Fujian Institute of Research \\ on the Structure of Matter, Chinese Academy of Sciences, Fuzhou 350002, P.R. China
}

Received March 15, 2012; Accepted May 4, 2012

DOI: $10.3892 / o r .2012 .1834$

\begin{abstract}
Hedyotis Diffusa Willd (HDW), a Chinese herbal medicine, has been widely used as an adjuvant therapy against various cancers, including hepatocellular carcinoma (HCC). However, the underlying anticancer mechanisms are yet to be elucidated. In the present study, the anticancer effects of HDW were evaluated and the efficacy and safety of HDW combined with low-dose 5-fluorouracil (5-FU) were investigated. HepG2 cells were cultured in vitro and nude mouse xenografts were established in vivo. The proliferation of HepG2 cells was measured using the MTT method and flow cytometry. The mRNA and protein expression levels of cyclin-dependent kinase 2 (CDK2), cyclin E and E2F1 were examined using relative quantitative real-time PCR and western blot analysis, respectively. The results showed that water extract of HDW remarkably inhibited HepG2 cell proliferation in a dosedependent manner via arrest of HepG2 cells at the G0/ G1 phase and induction of S phase delay. This suppression was accompanied by a great decrease of E2F1 and CDK2 mRNA expression. In addition, HDW remarkably potentiated the anti-
\end{abstract}

Correspondence to: Dr Jian Du or Dr Lian-Ming Liao, Academy of Integrative Medicine, Fujian University of Traditional Chinese Medicine, 1 Huatuo Road, Minhou Shangjie Town, Fuzhou 350108, P.R. China

E-mail: dujian@fjtcm.edu.cn

E-mail:1lm@fjtcm.edu.cn

Abbreviations: HDW, Hedyotis Diffusa Willd; HCC, hepatocellular carcinoma; 5-FU, 5-fluorouracil; CDK2, cyclin-dependent kinase 2; DMSO, dimethyl sulfoxide; MTT, methyl thiazolyl tetrazolium; PCR, polymerase chain reaction; HRP, horseradish peroxidase; PI, proliferating index

Key words: Hedyotis Diffusa Willd, hepatocellular carcinoma, 5-fluorouracil, CDK2, E2F1 cancer effect of low-dose 5-FU in the absence of overt toxicity by downregulating the mRNA and protein levels of CDK2, cyclin E and E2F1. Our findings support the use of HDW as adjuvant therapy of chemotherapy and suggest that HDW may potentiate the efficiency of low-dose 5-FU in treating HCC.

\section{Introduction}

Due to the high prevalence of hepatitis B and C virus infections in many countries, the incidence of hepatocellular carcinoma (HCC) is increasing and the mortality rate of HCC is extremely high in some countries (1). According to the data published by the International Agency for Research on Cancer, there were 564,000 HCC patients in 2000 and 55\% of which were in China (2). Curative treatments for HCC include surgery, local destruction techniques (radiofrequency ablation or percutaneous ethanol injection) and liver transplantation. Unfortunately, only $\sim 40 \%$ of patients can benefit from curative treatments and only $1 / 3$ of patients are typically resectable (3). Hence, for most patients with unresectable HCC, palliative treatments, which include transarterial chemoembolization, systemic therapy and radiotherapy are their only choices, and the survival rate and quality of life for them remain dismal $(4,5)$. Low efficacy and severe adverse effects still exist for chemotherapeutics. Development of more effective and less toxic antineoplastic agent remains an urgent task.

A meta-analysis has shown that patients simultaneously receiving chemotherapy and Chinese medicines may have higher 1-, 2- and 3-year survival rates (6). Indeed, many traditional Chinese medicines have long been used to fight various cancers and manage the side effects of chemotherapy for several decades. For instance, astragalus induced cancer cell apoptosis. It reversed the immunosuppressive effects of chemotherapy drugs by stimulating the production of interleukin-6 and TNF $(7,8)$.

Hedyotis Diffusa Willd (HDW) is an ancient Chinese medicine belonging to the Rubiaceae family, which is capable 
of heat-clearing, detoxification and activating blood according to the Chinese medicinal theory (9). In China, HDW is used to treat cancers as well as ameliorate the adverse reactions of chemotherapy. Pharmacological studies showed that it contains compounds with anticancer activities, including anthraquinones, hemiterpenes, flavones, polyphenols, organic acids and polysaccharides (10-12). Our previous study demonstrated that HDW extract inhibited angiogenesis and induced tumor cell apoptosis via the mitochondrion-dependent pathway $(13,14)$. By performing molecular docking simulation, we found that components in HDW (such as quercetin, asperuloside) could bind cyclin-dependent kinase 2 (CDK2) (15). CDK2 and downstream transcription factor $\mathrm{E} 2 \mathrm{~F} 1$ regulate the transition from $\mathrm{G} 1$ to $\mathrm{S}$ phase during cell proliferation (16). Inhibition of CDK2 activity can inhibit cell proliferation.

In this study, we showed that water extract of HDW was able to suppress the expression of CDK2 and E2F1 mRNA in HepG2 cells, which is consistent with molecular docking simulation. More importantly, our findings suggested that water extract of HDW effectively inhibited HepG2 cell growth in vivo and promote the anticancer efficiency of low-dose (5-fluorouracil) 5-FU via the inhibition of the CDK2-E2F1 pathway.

\section{Materials and methods}

Reagents. 5-FU was purchased from Tianjin King York Aminophenol, Inc. (Tianjin, China). HDW was purchased from Purapharm Co., Ltd. (Hong Kong, China). Specimens were authenticated by the Department of Pharmacy of Fujian University of Traditional Chinese Medicine (Fuzhou, China). To prepare the HDW water extract, HDW was steeped in 10 -fold volume of distilled water and decocted two times, 20 min each time. The aqueous extract was then filtered and concentrated to make a decoction, and subsequently stored at $4^{\circ} \mathrm{C}$ until use. Each milliliter of water extract was equivalent to $1.8 \mathrm{~g}$ crude HDW.

Animals. Forty female BALB/c nu/nu mice (6-weeks-old, 18-22 g) were purchased from Shanghai Slac Experimental Animal Co., Ltd. (Shanghai, China). The animals were maintained in a pathogen-free facility $\left(23 \pm 2^{\circ} \mathrm{C}, 55 \pm 5 \%\right.$ humidity). Animal care and experiment procedures were approved by the Ethics Committee of Fujian University of Traditional Chinese Medicine.

Cell line and culture. The HepG2 cell line was obtained from the Shanghai Institute of Life Science, Chinese Academy of Sciences (Shanghai, China), and was grown in high glucose DMEM (Gibco, Carlsbad, CA) supplemented with $10 \%$ fetal calf serum (Gibco).

MTT assay. To evaluate the effect of HDW on tumor cell proliferation, $1 \times 10^{4}$ HepG 2 cells were seeded in 96-well plates for $24 \mathrm{~h}$ and treated with HDW at the final concentrations of $0,1.25,2.5,5$ and $10 \mathrm{mg} / \mathrm{ml}$ for $24 \mathrm{~h}$. Then, $20 \mu \mathrm{l}$ of $5 \mathrm{mg} / \mathrm{ml}$ methyl thiazolyl tetrazolium (MTT) was added and incubated for another $4 \mathrm{~h}$ before it was discarded. The purple-blue MTT formazan precipitate was dissolved in $100 \mu \mathrm{l}$ dimethyl sulfoxide (DMSO). The absorbance was measured at $570 \mathrm{~nm}$. Cell viability was calculated according to the following formula: cell viability $(\%)=$ average $\mathrm{OD}_{\text {treatment group }}$ average $\mathrm{OD}_{\text {blank group }} \mathrm{x} 100 \%$.

Cell cycle assay. Cells were incubated in 6-well plates with either $4.62 \mathrm{mg} / \mathrm{ml} \mathrm{HDW}\left(\mathrm{IC}_{50}\right)$ or vehicle. They were referred to as HDW group and control group, respectively. After $24 \mathrm{~h}$, cells were digested and washed. Progression through the cell cycle was measured with flow cytometery (BD Biosciences, Franklin, NJ) according to the instructions of the Cycle-test Plus DNA assay kit (BD Biosciences). The percentages of cells in $\mathrm{G} 0 / \mathrm{G} 1, \mathrm{~S}$ and $\mathrm{G} 2 / \mathrm{M}$ phase were evaluated by the ModFit software (BD Biosciences). The proliferating index (PI) was calculated according to the following formula: $\mathrm{PI}=(\mathrm{S}+\mathrm{G} 2 / \mathrm{M}) /$ $(\mathrm{G} 0 / \mathrm{G} 1+\mathrm{S}+\mathrm{G} 2 / \mathrm{M}) \times 100 \%$.

Mouse xenograft experiments. BALB/c nu/nu mice were inoculated with $1 \times 10^{4} \mathrm{HepG} 2$ cells at the right flank and treatment was initiated when the estimated tumor volumes uniformly reached $\sim 50 \mathrm{~mm}^{3}$. The mice were randomly divided into 4 groups (n=10/group): low-dose 5-FU group, HDW group, combination group (HDW plus low-dose 5-FU) and vehicle control group, which received 5-FU $[10 \mathrm{mg} / \mathrm{kg} / \mathrm{day}$, intraperitoneally (i.p.)], HDW [6 g/kg/day, intragingivally (i.g.)], 5-FU (10 mg/kg/day, i.p.) plus HDW (6 g/kg/day, i.g.) and normal saline (NS, i.g.), respectively. The mouse body weight as well as tumor width (d) and length (D) were measured once every 3 days. Tumor volume (TV) was calculated by formula: $\mathrm{TV}\left(\mathrm{mm}^{3}\right)=\mathrm{d}^{2} \mathrm{xDx} 0.52$. After 4 weeks of treatment, blood from each mouse was collected, and the tumors were harvested and weighed. The levels of alanine aminotransferase (ALT), aspartate transaminase (AST), blood urea nitrogen (BUN) and creatinine (CRE) (Kehua, Shanghai, China) were measured by Biochemical Analyzer (Toshiba, Kawasaki, Japan). The tumor inhibitory rate (TIR) was calculated as follows: TIR $(\%)=\left[1\right.$-average tumor weight (treatment group) $_{\text {average tumor }}$ weight $\left._{\text {(vehicle group) }}\right]$ x100\%.

Quantitative real-time polymerase chain reaction $(P C R)$ examination. Total cellular RNA and tissular RNA were isolated using TRIzol one-step method as described in the manufacturer's recommendations (Invitrogen, Carlsbad, CA). Single-stranded cDNA was synthesized using oligo(dt) primer (Promega, Madison, WI) in a $20 \mu \mathrm{l}$ reaction mixture. The primer pairs of CDK2, E2F1, cyclin E and GAPDH were designed and synthesized as follows: E2F1, 5'-TGATACCCCAACTCCCTCTACC-3' and 5'-TGT CTCCCTCCCTCACTTTCC-3'; CDK2, 5'-CGCAAATG CTGCACTACGACC-3' and 5'-GCCCACCTGAGTCCAAATA GCC-3'; Cyclin E, 5'-TGACTGCCTTGAATTTCCTTATG-3' and 5'-GCACCACTGATACCCTGAAACC-3'; GAPDH, 5'-AC GGATTTGGTCGTATTGGGC-3' and 5'-CTCGCTCCTGGA AGATGGTGAT-3'. Real-time PCR was performed with power SYBR-Green I PCR Master mix kit (Applied Biosystems, Foster City, CA) by a 7500 real-time PCR system (Applied Biosystems). The relative quantitative PCR conditions for 40 cycles were performed as follow: denaturation at $95^{\circ} \mathrm{C}$ for $15 \mathrm{sec}$, anneal and extension at $60^{\circ} \mathrm{C}$ for $1 \mathrm{~min}$. After the amplification phase was completed, the melting curve examination was performed in order to eliminate non- 


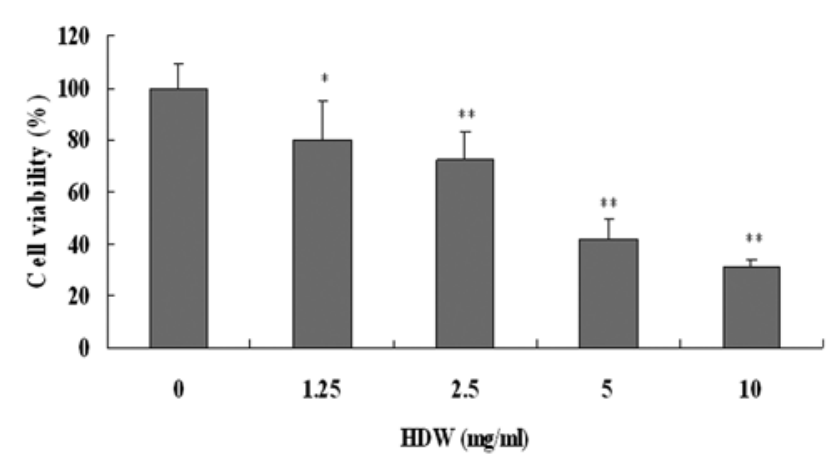

Figure 1. Effect of HDW on the viability of HepG2 cells. HepG2 cells were treated with different concentrations of HDW water extract for $24 \mathrm{~h}$. Data represent mean $\pm \mathrm{SD}$ of at least triplicate experiments. Compared with control cells ( $0 \mathrm{mg} / \mathrm{ml}$ group), ${ }^{*} \mathrm{P}<0.05,{ }^{* *} \mathrm{P}<0.01$, one-way ANOVA.

specific products. The fold change in gene expression of each sample was analyzed by SDS software (Applied Biosystems) using the equation $2^{-\Delta \Delta C t}$ method to calculate the relative level of each mRNA and expressed as a ratio relative to GAPDH housekeeper genes, where $\mathrm{Ct}$ value is the fractional cycle number at which the fluorescence exceeds that of background, and $\Delta \Delta \mathrm{Ct}=\left(\mathrm{Ct}_{\text {target }}-\mathrm{Ct}_{\mathrm{GAPDH}}\right)_{\text {sample }}-\left(\mathrm{Ct}_{\text {target }}-\mathrm{Ct}_{\mathrm{GAPDH}}\right)_{\text {control }}(17)$.

Western blot analysis. Tumor cells were put on dry ice for $10 \mathrm{~min}$ in lysis buffer. After centrifugation at $11,000 \mathrm{rpm}$ at $4^{\circ} \mathrm{C}$ for $20 \mathrm{~min}$, the supernatant was collected and the protein concentration determined using the Bradford assay. Equal amounts of denatured protein were separated on SDS-PAGE gels and transferred onto nitrocellulose (NC) membranes. The NC membranes were then put into blocking solution ( $1 \%$ bovine serum albumin) for $1 \mathrm{~h}$ and incubated in monoclonal anti-mouse CDK2, E2F1 or cyclin E primary antibody solutions (Santa Cruz Biotechnology, Inc., Santa Cruz, CA) or anti- $\beta$-actin antibody solution (Beyotime, Shanghai, China) overnight at $4^{\circ} \mathrm{C}$ with shaking, and then in horseradish peroxidase (HRP)-conjugated secondary antibody (Beyotime) for at least $1 \mathrm{~h}$. Chemiluminescence was detected using a Chemiluminescence imaging system (Bio-Rad, Hercules, CA).

Statistical analysis. The data were expressed as mean \pm SD of at least triplicate experiments. Double and multiple comparisons were performed using independent-samples t-test and one-way ANOVA, respectively. P-value $<0.05$ was considered significant. All results were analyzed using the SPSS 16.0 statistical software.

\section{Results}

HDW inhibits proliferation of Hep 2 cells in vitro. The effect of HDW on the proliferation of HepG2 cells was evaluated by MTT method. As shown in Fig. 1, in the presence of various concentrations of HDW, the proliferation of HepG2 was remarkably inhibited in a dose-dependent manner. The concentration of HDW to inhibit $50 \%$ cell growth $\left(\mathrm{IC}_{50}\right)$ was estimated to be $4.62 \mathrm{mg} / \mathrm{ml}$. The results demonstrated that water extract of HDW could markedly inhibit the proliferation of HepG2 cells.
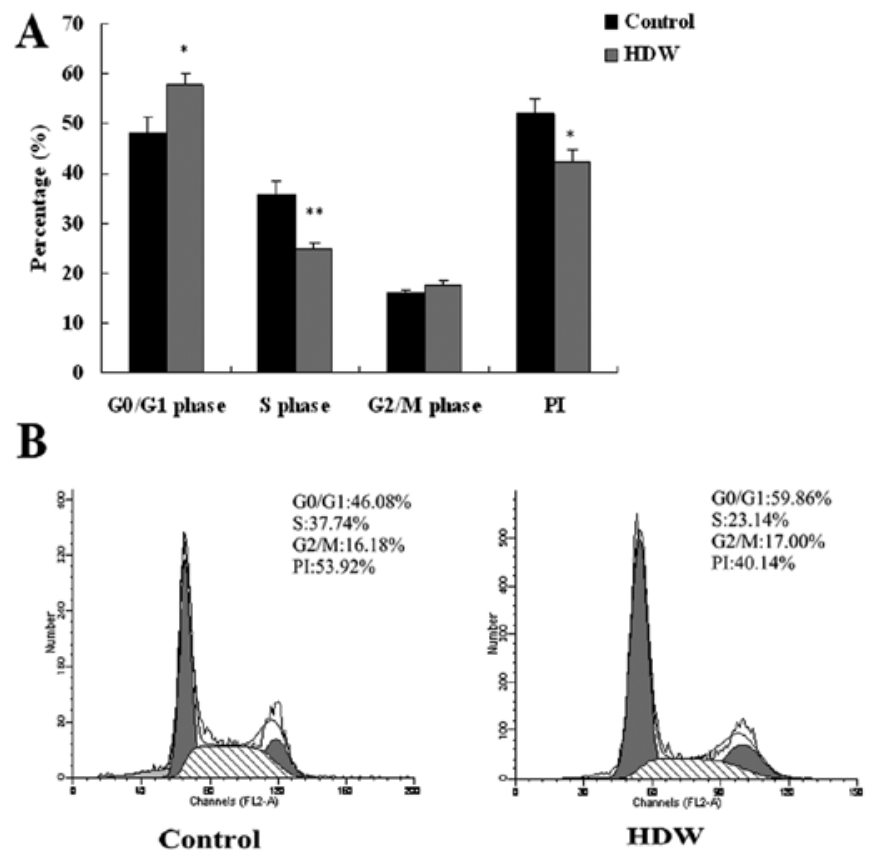

Figure 2. Effect of HDW on the cell cycle of HepG2 cells. Cells were treated with HDW water extract at a concentration of $4.62 \mathrm{mg} / \mathrm{ml}$ for $24 \mathrm{~h}$ and examined using flow cytometry with PI dye. (A) Compared with the control group, ${ }^{*} \mathrm{P}<0.05$ and ${ }^{* *} \mathrm{P}<0.01$, independent-samples t-test and (B) is representative of 3 experiments.

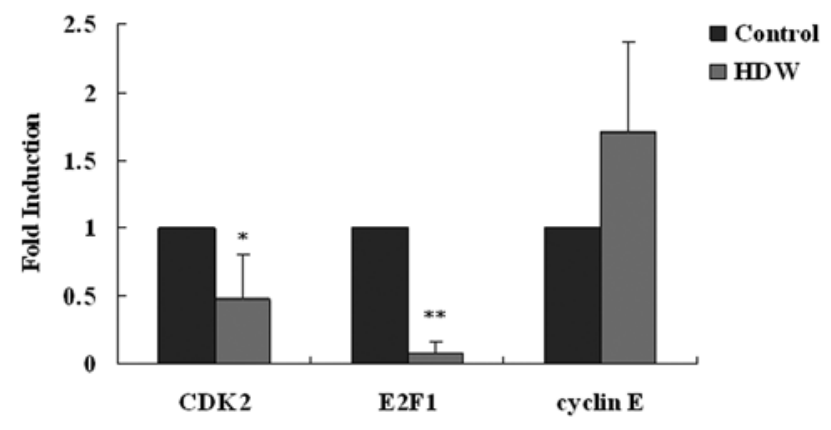

Figure 3. Effect of HDW on the mRNA expression of cell cycle regulators. HepG 2 cells were cultured in the presence or absence of $4.62 \mathrm{mg} / \mathrm{ml} \mathrm{HDW}$ water extract for $24 \mathrm{~h}$ in vitro. Real-time PCR was performed with GAPDH as an internal positive control. The data for HDW-treated samples were expressed relative to the average value of the control samples \pm standard deviations of the means. Compared with the control group, ${ }^{*} \mathrm{P}<0.05$ and ${ }^{* *} \mathrm{P}<0.01$, independent-samples t-test.

HDW arrests HepG2 cells at G0/G1 phase and induces $S$ phase delay. Progression through the cell cycle was examined using flow cytometry and the results are shown in Fig. 2. When HepG2 cells were treated with $4.62 \mathrm{mg} / \mathrm{ml} \mathrm{HDW}\left(\mathrm{IC}_{50}\right)$, the percentage of cells in G0/G1 phase increased from 48.16 $\pm 3.11-57.71 \pm 2.29 \%$ $(\mathrm{P}<0.05)$. On the contrary, the percentage of cells in $\mathrm{S}$ phase decreased from $35.73 \pm 2.56-24.71 \pm 1.43 \%$ ( $\mathrm{P}<0.01)$. As expected, PI in the HDW group was lower than that of the control group $(42.29 \pm 2.30 \%$ vs. $51.85 \pm 3.11 \%, \mathrm{P}<0.05)$. These results demonstrated that HDW inhibited the proliferation of HepG2 cells by inducing G0/G1 phase arrest and S phase delay. 
A

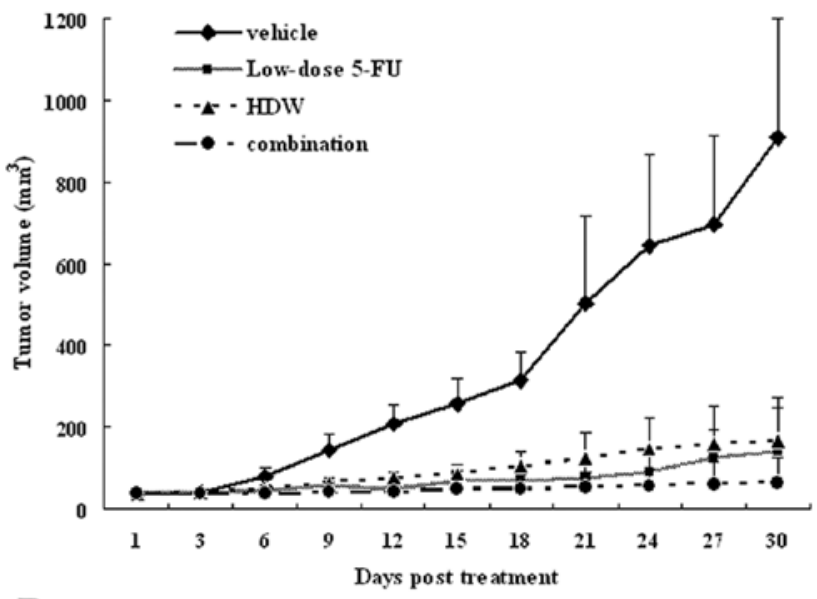

B

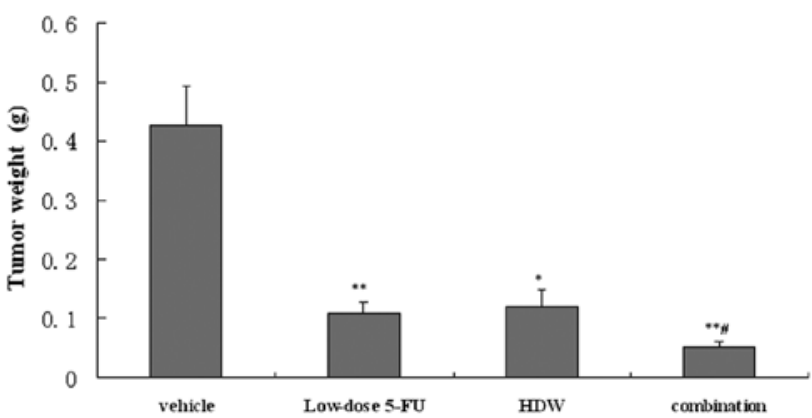

Figure 4. Effects of HDW on tumor growth. The tumor-bearing nude mice were treated with low-dose 5-FU (low-dose 5-FU group), HDW (HDW group), low-dose 5-FU plus HDW (combination group) and normal saline (vehicle control group) respectively. (A) Tumor volume analysis once every 3 days and (B) tumor weight at sacrifice. The values were expressed as mean $\pm \mathrm{SD},{ }^{*} \mathrm{P}<0.05$ and ${ }^{* *} \mathrm{P}<0.01$ vs. the vehicle group, ${ }^{\#} \mathrm{P}<0.05$ vs. the low-dose $5-\mathrm{FU}$ group.

$H D W$ downregulates the expression of $C D K 2$ and $E 2 F 1$ mRNA of HepG2 cells. CDK2, cyclin E and E2F1 transcription factor play critical roles in cell cycle progression from G0/G1 to S phase. To investigate how HDW interferred G1/S transition of HepG2 cell cycle, expression of CDK2, E2F1 and cyclin E mRNA was evaluated with relative quantitative real-time PCR. As shown in Fig. 3, the levels of CDK2 and E2F1 mRNA decreased to 48 and $0.08 \%$, respectively by HDW. However, HDW did not affect the transcription of cyclin E mRNA. These results suggested that HDW induced G0/G1 phase arrest and S phase delay of HepG2 cells at least partly through the CDK2-E2F1 pathway in vitro.

Assessment of anticancer effects of HDW alone or in combination with low-dose 5-FU in vivo. The reason of testing HDW for treatment of $\mathrm{HCC}$ is to see if HDW can be used as an adjuvant therapeutic agent in combination with low-dose chemotherapy, which is not as effective as standard-dose therapy. To evaluate the effects of HDW on tumor growth and if it could enhance the effect of low-dose 5-FU, the leading chemotherapeutic drug for advanced HCC, we examined tumor xenograft volume once every 3 days after initial treatment and tumor weight at sacrifice. As shown in Fig. 4A, all treatment groups showed
A

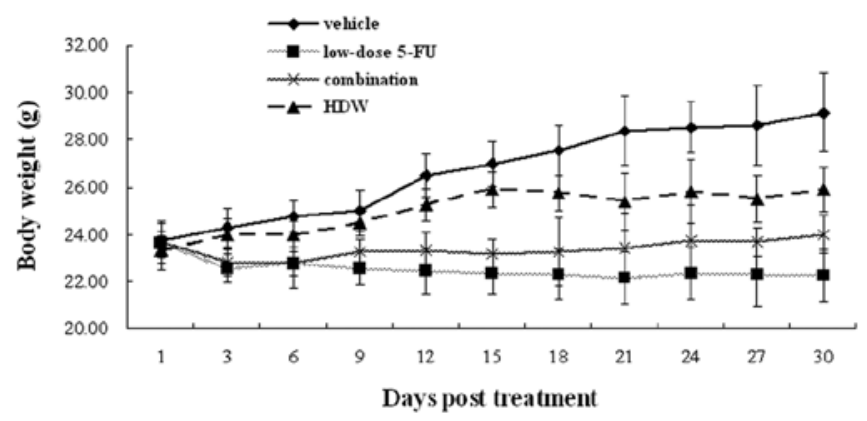

B

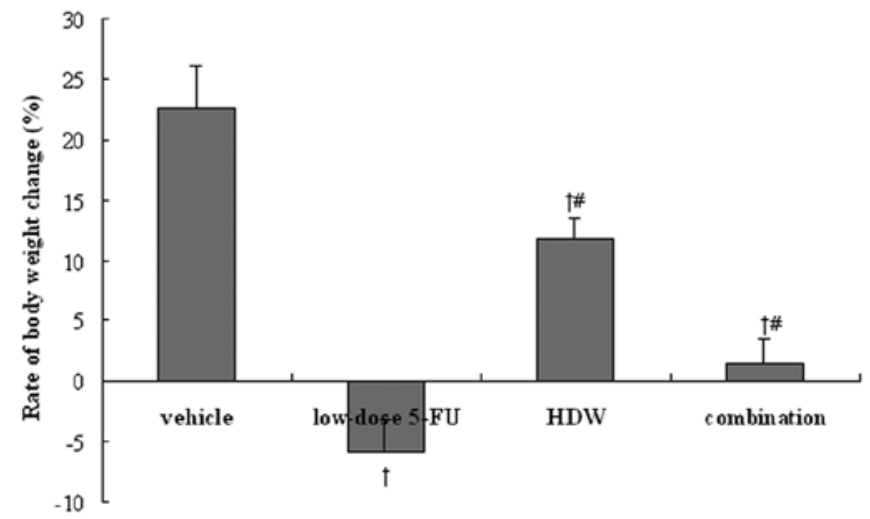

Figure 5. Evaluation of toxicity of HDW and combination therapy. (A) Body weight of the mice was measured once every 3 days after initial treatment and (B) the rate of body weight change (RBW) was calculated by the formula: RBW $(\%)=[($ BWon sacrifice $)-($ BWon initial treatment $)] /$ (BWon initial treatment) $\mathrm{x} 100 \%$. ${ }^{\dagger} \mathrm{P}<0.01$ vs. the vehicle group. ${ }^{*} \mathrm{P}<0.01$ vs. the low-dose 5-FU group.

tumor growth delay as assessed by tumor volume changes. At sacrifice, the tumor volume was $909.92 \pm 289.99 \mathrm{~mm}^{3}$ in the vehicle group, $139.73 \pm 104.46 \mathrm{~mm}^{3}$ in the low-dose 5-FU group, $165.35 \pm 106.17 \mathrm{~mm}^{3}$ in the HDW group and $65.92 \pm 59.34 \mathrm{~mm}^{3}$ in the combination group. Thus, either HDW or low-dose 5-FU could significantly inhibit the tumor growth. When they were simultaneously administered, a higher inhibition was achieved $(\mathrm{P}<0.01)$. A similar tendency was observed when the tumor weights were compared among the 4 groups (Fig. 4B). The TIR was $74.51 \%$ in the low-dose 5-Fu group, $71.83 \%$ in the HDW group and $87.87 \%$ in the combination group, respectively. The anticancer efficacy of HDW was comparable to low-dose 5-FU. Furthermore, HDW potentiated the effect of low-dose 5-FU.

Evaluation of toxicity of HDW and combined therapy. We also investigated the gross toxicity of HDW alone or HDW combined with low-dose 5-FU in tumor-bearing mice. As tumor growth progressed, mice in all groups gradually showed signs of dullness, inertia, dim skin color, etc. The body weights of tumor-bearing mice in each group are shown in Fig. 5. At sacrifice, body weight decreased by $5.92 \pm 2.79 \%$ in the lowdose 5-FU group. On the contrary, the body weight increased by $22.65 \pm 3.42 \%$ in the vehicle group, $11.79 \pm 1.81 \%$ in the HDW 
Table I. Hepatorenal toxicity of low-dose 5-FU, HDW and a combination of low-dose 5-FU and HDW.

\begin{tabular}{lcccr}
\hline Groups & ALT (IU/l) & AST (IU/l) & BUN $(\mathrm{mmol} / \mathrm{l})$ & CRE $(\mu \mathrm{mol} / \mathrm{l})$ \\
Vehicle & $58.44 \pm 15.00$ & $217.88 \pm 53.20$ & $8.07 \pm 1.05$ & $31.36 \pm 6.50$ \\
Low-dose 5-FU & $58.70 \pm 17.70$ & $206.10 \pm 55.40$ & $7.89 \pm 1.70$ & $35.96 \pm 8.30$ \\
HDW & $72.00 \pm 15.19$ & $216.50 \pm 54.87$ & $7.13 \pm 0.76$ & $31.48 \pm 5.17$ \\
Combination & $62.00 \pm 12.65$ & $202.00 \pm 26.44$ & $9.78 \pm 2.20$ & $36.08 \pm 4.16$ \\
\hline
\end{tabular}

ALT, alanine aminotransferase; AST, aspartate transaminase; BUN, blood urea nitrogen; CRE, creatinine.

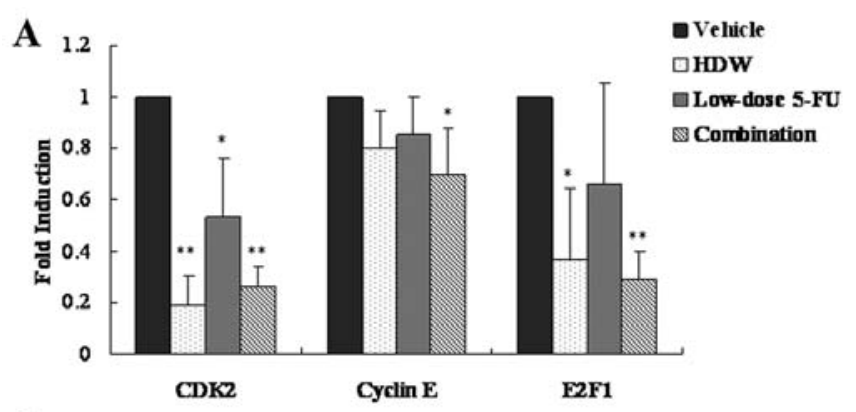

B

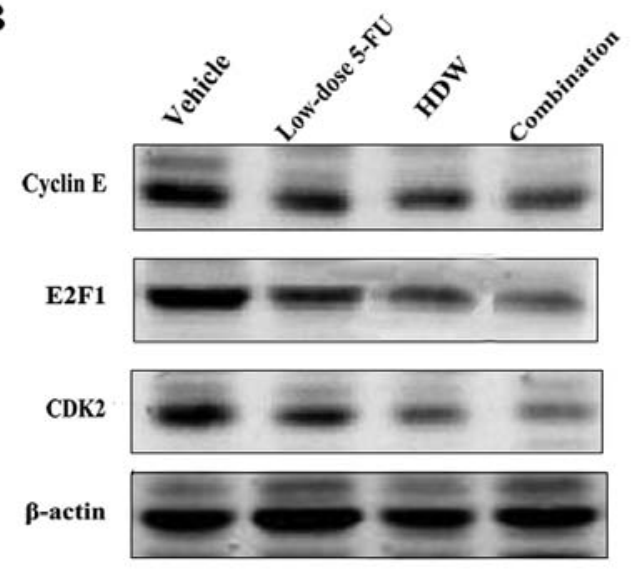

Figure 6. Effect of HDW on expression of cell cycle regulators. The levels of CDK2, E2F1 and cyclin E were determined with (A) relative quantitative real-time PCR and (B) western blot analysis. The values were expressed as mean $\pm \mathrm{SD},{ }^{*} \mathrm{P}<0.05$ and ${ }^{* *} \mathrm{P}<0.01$ vs. the vehicle group.

group and $1.39 \pm 2.15 \%$ in the combination group. No overt toxicity in liver and kidney function was observed in each group (Table I). These results indicate that addition of HDW to low-dose 5-FU does not increase the toxicity of the latter.

HDW and combination therapy downregulate the expressions of cell cycle regulators in vivo. As shown above, HDW treatment downregulated the expressions of CDK2 and E2F1 mRNA of HepG2 cells in vitro. Here we further investigated HDW alone and HDW combined with low-dose 5-FU on the expression of CDK2, E2F1 and cyclin E in vivo using both western blot analysis and real-time PCR. The results are shown in Fig. 6. Compared with the vehicle group, HDW markedly downregulated the expression levels of CDK2 and E2F1 mRNA. Low-dose 5-FU significantly decreased the expression level of CDK2 mRNA but showed no effects on E2F1 and cyclin E mRNA expression.
As expected, a combination of HDW and low-dose 5-FU caused a greater decrease in the expression levels of CDK2 and E2F1 mRNA (Fig. 6A). Expression of cyclin E was also decreased in the combination group. These results were further supported by western blot analysis (Fig. 6B), indicating that HDW enhanced the efficacy of low-dose 5-fluorouracil by further inhibiting the CDK2-E2F1 pathway.

\section{Discussion}

5-FU-based regimens as standard treatment have been widely used clinically in the treatment of various solid tumors, such as colorectal cancer (18), HCC (19), breast cancer (20) and glioma (21). Clinical trials have proven that 5-FU-based chemotherapy significantly improves overall and disease-free survival of such patients (22). Despite these favorable results, low response rate (13\%) (23), resistance (24), short half-life (10 min) (25), severe cytotoxic and immunosuppressive adverse reactions (26-29) limit its clinical application. Recently, the regimens of low-dose-based chemotherapy have been used against cancers with relatively mild toxicities (30-37). For example, regimen with low-dose 5-fluorouracil and cisplatin has been reported to improve the median survival time of patients with advanced HCC (36). Patients with unresectable squamous cell carcinoma of the esophagus also had favorable overall survival when treated with low-dose cisplatin and continuous infusion of 5-FU (37). Unfortunately, low-dose chemotherapy regimens are still undoubtedly less effective than standard-dose therapy regimens.

The use of Chinese medicine as adjuvant treatment of chemotherapy has many advantages over chemotherapy alone, such as enhancement of the anticancer effects and reduction of the side effects of chemotherapy and improvement of patients' quality of life (38). HDW, an important component in many anticancer formulas of traditional Chinese medicine, has been verified by many researchers $(7,39)$. However, its anticancer mechanism still remains largely unknown. Our findings showed that HDW could inhibit the growth of HepG2 cells both in vitro and in vivo. It can arrest HepG2 cells at G0/G1 phase and induce S phase delay at least partly through the CDK2-E2F1 pathway. In addition, we found in animal experiments that although its antineoplastic effect was lower than low-dose 5-FU, it might enhance the antitumor effect of the latter in the absence of overt toxicity, indicating that HDW might be a promising adjuvant therapy for chemotherapy.

The CDK2-E2F1 pathway is critical in regulating the transition of $\mathrm{G} 1$ to $\mathrm{S}$ phase of cell cycle. CDK2 is one of 
the members of cyclin-dependent kinases (CDKs). When CDK2 associates with cyclin E, its serine-threonine kinase activity is activated $(40,41)$ and the conjunction facilitates phosphorylation of retinoblastoma protein with the release of the E2F1 transcription factor (42). The release of the E2F1 transcription factor drives cells through $\mathrm{G} 1$ into $\mathrm{S}$ phase and promotes cell cycle progression (43). The control of the pathway is disrupted in virtually all human cancers (44), including HCC (45). Several studies have demonstrated that the growth of cancer cells could be inhibited via downregulating the mRNA or protein levels of CDK2, cyclin E or E2F1 transcription factor. For example, Tin et al (46) reported that artemisinin inhibited the proliferation of breast cancer cells via selectively downregulating the levels of the CDK2 and CDK4, cyclin E, cyclin D1 and the E2F1 transcription factor. Fang et al (47) reported that acetylbritannilactone inhibited the growth of HT-29 human colon cancer cells by inducing cell cycle arrest in G0/G1 phase and this suppression was accompanied by a marked decrease of cyclin E and CDK4 protein levels.

In this study, we observed the effect of HDW on the transcription and protein levels of CDK2, cyclin E and E2F1 involved in $\mathrm{CDK} 2 / \mathrm{Rb} / \mathrm{E} 2 \mathrm{~F}$ signaling. Our results showed that HDW interfered the G1/S transition of HepG2 cells at least via downregulation of the transcript and protein levels of CDK2 and E2F1 transcription factor. The results are consistent with our data of molecular docking simulation (15). Furthermore, we also found in vivo low-dose 5-FU could inhibit the expression of CDK2, as reported by others (18). However, it had no effect on the levels of cyclin E and E2F1 transcription factor. Combined with HDW, low-dose 5-FU more remarkably downregulated not only CDK2 but also E2F1 transcription factor and cyclin E. This may partially explain why HDW can enhance the antiproliferative effect of low-dose 5-FU.

In the present study, we also found that administration of low-dose 5-FU alone caused diarrhea in the mice (data not shown) and suppressed body weight gain. Indeed, studies showed that the use of low-dose 5-FU was still associated with many adverse effects, such as mucositis (18\%) and diarrhea $(39 \%)$ (48), which may be the possible reason of weight loss. However, when the mice were treated with the combination of HDW and low-dose 5-FU, the effect was reversed. Wang et al (49) reported that HDW could protect the gastrointestinal mucosa. We thus hypothesize that HDW could protect against low-dose 5-FU-induced weight loss by preventing injury to the gastrointestinal mucosa that otherwise would cause diarrhea.

In conclusion, HDW remarkably enhanced the antitumor effect of low-dose 5-FU by inhibiting the CDK2-E2F1 pathway in the absence of overt toxicity. These findings provide important data for further testing the possibility of using HDW as adjuvant therapy for clinical HCC patients. Further studies are necessary to elucidate the compounds in HDW which are responsible for such synergism.

\section{Acknowledgements}

The study was supported by the International Science Joint Project, the Ministry of Science and Technology of the People's
Republic of China (no. 2008DFA32200), the National Natural Science Foundation of China (no. 81102582), the Fujian Province Natural Science Foundation (no. 2009J01170), the Chen Keji Integrative Medicine Developmental Foundation (no. CKJ2008002) and the Open Fund of Fujian Key Laboratory of Integrative Medicine on Geriatrics (2008J100415ckj2008052).

\section{References}

1. Llovet JM, Burroughs A and Bruix J: Hepatocellular carcinoma. Lancet 362: 1907-1917, 2003.

2. Parkin DM: Global cancer statistics in the year 2000. Lancet Oncol 2: 533-543, 2001.

3. Gish RG and Baron A: Hepatocellular carcinoma (HCC): current and evolving therapies. IDrugs 11: 198-203, 2008.

4. Llovet J, Di Bisceglie A, Bruix J, Kramer B, Lencioni R, Zhu A Sherman M, Schwartz M, Lotze M, Talwalkar J and Gores GJ: Design and endpoints of clinical trials in hepatocellular carcinoma. J Natl Cancer Inst 100: 698-711, 2008.

5. DuBray BJ Jr, Chapman WC and Anderson CD: Hepatocellular carcinoma: a review of the surgical approaches to management. Mo Med 108: 195-198, 2011.

6. Shu X, McCulloch M, Xiao H, Broffman M and Gao J: Chinese herbal medicine and chemotherapy in the treatment of hepatocellular carcinoma:a meta-analysis of randomized controlled trials. Integr Cancer Ther 4: 219-229, 2005.

7. Yoshida Y, Wang MQ, Liu JN, Shan BE and Yamashita U: Immunomodulating activity of Chinese medicinal herbs and Oldenlandia diffusa in particular. Int J Immunopharmacol 19: 359-370, 1997.

8. Song Y, Yang J, Bai WL and Ji WY: Antitumor and immunoregulatory effects of astragalus on nasopharyngeal carcinoma in vivo and in vitro. Phytother Res 25: 909-915, 2011.

9. Wu YG and Song LR: Zhong hua ben cao. Shanghai Sciece and Technology Press, Shanghai, pp1530-1533, 1998.

10. Zhang YY and Luo JB: Analysis of the chemical constituents of Hedyotis diffusa. Nan Fang Yi Ke Da Xue Xue Bao 28: 127-128, 2008 (In Chinese).

11. Lee HZ, Bau DT, Kuo CL, Tsai RY, Chen YC and Chang YH: Clarification of the phenotypic characteristics and anti-tumor activity of Hedyotis diffusa. Am J Chin Med 39: 201-213, 2011.

12. Huang W, Li Y and Jiang J: Chemical constituents from Hedyotis diffusa. Zhongguo Zhong Yao Za Zhi 34: 712-714, 2009 (In Chinese).

13. Lin J, Chen Y, Wei L, Chen X, Xu W, Hong Z, Sferra TJ and Peng J: Hedyotis Diffusa Willd extract induces apoptosis via activation of the mitochondrion-dependent pathway in human colon carcinoma cells. Int J Oncol 37: 1331-1338, 2010.

14. Lin J, Wei L, Xu W, Hong Z, Liu X and Peng J: Effect of Hedyotis Diffusa Willd extract on tumor angiogenesis. Mol Med Rep 4: 1283-1288, 2011.

15. Chen L, Zheng C and Du J: Study on antitumor mechanism of Qingre Xiaozheng drink by molecular docking method. Chin J Clin Pharmacol Ther 12: 324-328, 2007.

16. Wadler S: Perspectives for cancer therapies with cdk2 inhibitors. Drug Resist Updat 4: 347-367, 2001.

17. Livak KJ and Schmittgen TD: Analysis of relative gene expression data using real-time quantitative PCR and the 2(-Delta Delta C(T)) method. Methods 25: 402-408, 2001.

18. Sasaki K, Tsuno NH, Sunami E, Tsurita G, Kawai K, Okaji Y, Nishikawa T, Shuno Y, Hongo K, Hiyoshi M, et al: Chloroquine potentiates the anti-cancer effect of 5-fluorouracil on colon cancer cells. BMC Cancer 10: 370, 2010.

19. Uka K, Aikata H, Takaki S, Kawaoka T, Saneto H, Miki D, Takahashi S, Toyota N, Ito K and Chayama K: Systemic gemcitabine combined with intra-arterial low-dose cisplatin and 5-fluorouracil for advanced hepatocellular carcinoma: Seven cases. World J Gastroenterol 14: 2602-2608, 2008.

20. Hutchins LF, Green SJ, Ravdin PM, Lew D, Martino S, Abeloff M, Lyss AP, Allred C, Rivkin SE and Osborne CK: Randomized, controlled trial of cyclophosphamide, methotrexate, and fluorouracil versus cyclophosphamide, doxorubicin, and fluorouracil with and without tamoxifen for high-risk, node-negative breast cancer: treatment results of Intergroup Protocol INT-0102. J Clin Oncol 23: 8313-8321, 2005. 
21. Shapiro WR, Green SB, Burger PC, Selker RG, VanGilder JC, Robertson JT, Mealey J Jr, Ransohff J and Mahaley MS Jr: A randomized comparison of intra-arterial versus intravenous BCNU, with or without intravenous 5-fluorouracil, for newly diagnosed patients with malignant glioma. J Neurosurg 76: 772-781, 1992.

22. Tsai WS, Hsieh PS, Yeh CY, Chiang JM, Tang R, Chen JS, Changchien CR and Wang JY: Impact of chemotherapy-related prognostic factors on long-term survival in patients with stage III colorectal cancer after curative resection. Int J Clin Oncol: Jan 20 2012 (Epub ahead of print). doi: 10.1007/s10147-011-0370-8.

23. Stehlin JS Jr, de Ipolyi PD, Greeff PJ, McGaff CJ Jr, Davis BR and McNary L: Treatment of cancer of the liver. Twenty years experience with infusion and resection in 414 patients. Ann Surg 208: 23-35, 1988.

24. Wang W, Cassidy J, O'Brien V, Ryan KM and Collie-Duguid E: Mechanistic and predictive profiling of 5-fluorouracil resistance in human cancer cells. Cancer Res 64: 8167-8176, 2004.

25. Regazzoni S, Pesce G, Marini G, Cavalli F and Goldhirsch A: Low-dose continuous intravenous infusion of 5-fluorouracil for metastatic breast cancer. Ann Oncol 7: 807-813, 1996

26. Cameron DA, Gabra H and Leonard RC: Continuous 5-fluorouracil in the treatment of breast cancer. Br J Cancer 70: 120-124, 1994.

27. Lokich J, Bothe A, Fine N and Perri J: Phase I study of protracted venous infusion of 5-fluorouracil. Cancer 48: 2565-2568, 1981.

28. Lemon HM: Reduction of 5-fluorouracil toxicity in man with retention of anticancer effects by prolonged intravenous administration in 5\% dextrose. Cancer Chemother Rep 8: 97-101, 1960

29. Ng JS, Cameron DA and Leonard RC: Infusional 5-fluorouracil in breast cancer. Cancer Treat Rev 20: 357-364, 1994.

30. Huan S, Pazdur R, Singhakowinta A, Samal B and Vaitkevicius VK: Low-dose continuous infusion 5-fluorouracil evaluation in advanced breast carcinoma. Cancer 63: 419-422, 1989.

31. Munoz R, Man S, Shaked Y, Lee CR, Wong J, Francia G and Kerbel RS: Highly efficacious nontoxic preclinical treatment for advanced metastatic breast cancer using combination oral UFT-cyclophosphamide metronomic chemotherapy. Cancer Res 66: 3386-3391, 2006.

32. Iwamoto $H$, Torimura $T$, Nakamura $T$, Hashimoto $O$, Inoue $K$, Kurogi J, Niizeki T, Kuwahara R, Abe M, Koga H, et al: Metronomic S-1 chemotherapy and vandetanib: An efficacious and nontoxic treatment for hepatocellular carcinoma. Neoplasia 13: 187-197, 2011

33. Tanioka H, Tsuji A, Morita S, Horimi T, Takamatsu M, Shirasaka T, Mizushima T, Ochi K, Kiura K and Tanimoto M: Combination chemotherapy with continuous 5-fluorouracil and low-dose cisplatin infusion for advanced hepatocellular carcinoma. Anticancer Res 23: 1891-1897, 2003.

34. Ueshima K, Kudo M, Takita M, Nagai T, Tatsumi C, Ueda T, Kitai S, Ishikawa E, Yada N, Inoue T, et al: Hepatic arterial infusion chemotherapy using low-dose 5-fluorouracil and cisplatin for advanced hepatocellular carcinoma. Oncology 78 : $148-153,2010$
35. Lai YC, Shih CY, Jeng CM, Yang SS, Hu JT, Sung YC, Liu HT, Hou SM, Wu CH and Chen TK: Hepatic arterial infusion chemotherapy for hepatocellular carcinoma with tumor thrombosis of the portal vein. World J Gastroenterol 9: 2666-2670, 2003.

36. Tang TC, Man S, Xu P, Francia G, Hashimoto K, Emmenegger U and Kerbel RS: Development of a resistance-like phenotype to sorafenib by human hepatocellular carcinoma cells is reversible and can be delayed by metronomic UFT chemotherapy. Neoplasia 12: 928-940, 2010

37. Takagawa R, Kunisaki C, Makino H, Kosaka T, Ono HA, Akiyama $\mathrm{H}$ and Shimada $\mathrm{H}$ : Efficacy of chemoradiotherapy with low-dose cisplatin and continuous infusion of 5-fluorouracil for unresectable squamous cell carcinoma of the esophagus. Dis Esophagus 22: 482-489, 2009.

38. Konkimalla VB and Efferth T: Evidence-based Chinese medicine for cancer therapy. J Ethnopharmacol 116: 207-210, 2008.

39. Gupta S, Zhang D, Yi J and Shao J: Anticancer activities of Oldenlandia diffusa. J Herb Pharmacother 4: 21-33, 2004

40. Koff A, Giordano A, Desai D, Yamashita K, Harper JW, Elledge S, Nishimoto T, Morgan DO, Franza BR and Roberts JM: Formation and activation of a cyclin E-cdk2 complex during the G1 phase of the human cell cycle. Science 257: 1689-1694, 1992.

41. D'Urso G, Marraccino RL, Marshak DR and Roberts JM: Cell cycle control of DNA replication by a homologue from human cells of the p34cdc2 protein kinase. Science 250: 786-791, 1990.

42. Sherr CJ: Cancer cell cycles. Science 274: 1672-1677, 1996.

43. Weinberg RA: E2F and cell proliferation: a world turned upside down. Cell 85: 457-459, 1996.

44. Nevins JR: The Rb/E2F pathway and cancer. Hum Mol Genet 10 699-703, 2001.

45. Matsuda Y: Molecular mechanism underlying the functional loss of cyclindependent kinase inhibitors p16 and p27 in hepatocellular carcinoma. World J Gastroenterol 14: 1734-1740, 2008

46. Tin AS, Sundar SN, Tran KQ, Park AH, Poindexter KM and Firestone GL: Antiproliferative effects of artemisinin on human breast cancer cells requires the downregulated expression of the E2F1 transcription factor and loss of E2F1-target cell cycle genes. Anticancer Drugs 23: 370-379, 2012

47. Fang XM, Liu B, Liu YB, Wang JJ, Wen JK, Li BH and Han M: Acetylbritannilactone suppresses growth via upregulation of krüppel-like transcription factor 4 expression in HT-29 colorectal cancer cells. Oncol Rep 26: 1181-1187, 2011.

48. Smith IE, Johnston SR, O'Brien ME, Hickish TF, de Boer RH, Norton A, Cirkel DT and Barton CM: Low-dose oral fluorouracil with eniluracil as first-line chemotherapy against advanced breast cancer: a phase II study. J Clin Oncol 18: 2378-2384, 2000.

49. Wang GY, Li ZB, Shi JX, Wang H, Gao QF, Gen LF, Zhu JJ and Zhao QS: Oldenlandia diffusa protects against indomethacininduced injury of the gastrointestinal mucosa in rats. Hebei J Tradit Chin Med 23: 70-71, 2001 (In Chinese). 